\title{
SURROGACY IN SOUTH AFRICA
}

\author{
Julia SLOTH-NieLSEN
}

1. General Legal Framework ........................... 185

2. Surrogacy Arrangements in General . . . . . . . . . . . . . . . . . . 187

3. Legal Parenthood at the Time of Birth .................... 191

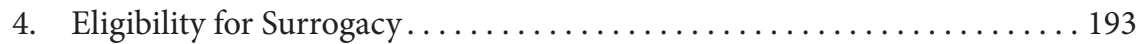

4.1. Eligibility Criteria for Women Acting as a Surrogate ........... 193

4.2. Eligibility Criteria for Commissioning Parents . . . . . . . . . . . . 194

4.3. Role of the Child's Best Interests in Assessing Eligibility . . . . . . . . 194

5. Transferring Parenthood .............................. 195

5.1. Legal Process. ............................... 195

5.2. Rights of Children ............................ 196

6. Agencies and Criminalisation .......................... 196

7. International Surrogacy Arrangements . . . . . . . . . . . . . . . 199

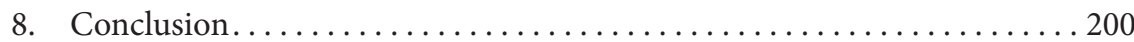

\section{GENERAL LEGAL FRAMEWORK}

Steps to regulate surrogacy in South Africa predate the advent of democracy. In 1987, in a much publicised case, Karen Ferreira Jorge gave birth to triplets, born of the gametes of her daughter (she was the gestational mother and the biological grandmother). At the time there was no legal regulation for this unprecedented state of events, leading to a project committee of the South African Law Commission (now the South African Law Reform Commission (hereafter 'SALRC') being appointed to investigate the issue. Although this Committee had completed its work in the $1990 \mathrm{~s},{ }^{1}$ there was no further legislative action (notwithstanding a post-1994 Ad Hoc Parliamentary Committee being convened to conduct public hearings on surrogacy) to finalise new laws.

Draft Bill on Surrogate Motherhood, proposed by SALRC, GN 512 GG 16479, 14 June 1995. 
Ultimately surrogacy was added as a final chapter to the Children's Act 37 of 2005, which came fully into force in April 2010. The project committee which had deliberated upon the development of the omnibus Children's Act had not considered surrogacy during its lifespan, so the impetus to add surrogacy to the Children's Act came from within the SALRC. The initial work of the SALRC has survived, and many of the current provisions can be traced to the original report. The location of regulations on surrogacy within the overarching tenets of the Children's Act has, however, shaped the current interpretation of the provisions, as will be shown below. By way of a preliminary point, the Act allows only altruistic surrogacy: commercial surrogacy is barred.

South Africa stands out for its progressive constitution, with two particular clauses worthy of discussion. First, s. 28 provides a mini charter of children's rights, including the injunction that the best interests of the child are of paramount concern in all matters affecting the child. As a justiciable constitutional right, the best interests provision has provided an important standard which has at times been overriding. Second, South Africa's equality clause (s. 9) prohibits discrimination on a wide range of bases, including gender, marital status and sexual orientation. All have proved to be relevant in the context of surrogacy, which is equally available to hetero and same-sex couples.

Apart from the Children's Act, of added relevance are the Regulations Relating to the Artificial Fertilisation of Persons ${ }^{2}$ promulgated by the Minister of Health under the Health Act 2003. ${ }^{3}$

There are no available statistics to indicate how many surrogacy agreements are concluded annually in the country. Since the Children's Act requires confirmation of surrogacy agreement prior to fertilisation of the surrogate by a High Court, of which there are more than 12 in the country, it could be possible to establish a quantum, but that would require perusal of the documents at each court. Since fertility clinics are mainly in private hands, data from that source is not available either.

However, both the requirement of a written agreement, which would necessarily be prepared by an attorney, ${ }^{4}$ and the requirement of a High Court application which is costly, means that generally surrogacy will be the preserve of the middle and upper classes, and figures are estimated to be fairly low (in the tens or hundreds rather than thousands).

2 R 175 of Government Gazette no. 1165 of 20.09.2016, read together with R 175 of Government Gazette no. 35099 of 12.03.2012.

3 Act 61 of 2003. Section 296(2) of the Children's Act provides that the fertilisation of any person in consequence of the confirmation of a surrogate agreement must be effected in terms of these regulations.

4 See the stringent requirements for papers laid down in the first reported surrogacy matter, Ex Parte WH and others 2011 (6) SA 514. 


\section{SURROGACY ARRANGEMENTS IN GENERAL}

With the coming into force of Chapter 20 of the Children's Act, surrogacy agreements acquired legal validity, provided that the various requirements established by the Act are met. First, the agreement must be in writing, and signed by all the parties. ${ }^{5}$ Of primary importance is that only non-commercial surrogacy (altruistic) is permitted, as will be further detailed below.

The contractual agreement must be entered into in South Africa, and at least one of the commissioning parents, or where the commissioning parent is a single person, that person, must be domiciled in South Africa. ${ }^{6}$ So, too, the surrogate and her husband or partner, if any, must be domiciled in South Africa at the time of entering into the agreement. ${ }^{7}$ The intention of the legislator was clearly to prevent South Africa from becoming an international surrogacy destination.

Further, where a commissioning parent is married or is involved in a permanent relationship, a court may not confirm an agreement unless that husband, wife or partner gives consent to the agreement and becomes party to it. Similarly, the husband or partner of the surrogate must consent and become party to the agreement. ${ }^{8}$

Before proceeding to detail the requirements of s. 294, s. 295 provides what the Constitutional Court of South Africa has termed the 'threshold requirement'. This entails that the commissioning parent or parents must not be able to give birth to a child and that such condition must be permanent and irreversible. A person is 'conception infertile' if they are unable to contribute a gamete 9 for the purposes of conception through artificial fertilisation. A person is 'pregnancy infertile' if they are permanently and irreversibly unable to carry a pregnancy to term. In other words, both situations would meet the requirements of s. 295(a) of the Children's Act.

Section 294 contains the now famous genetic link requirement: no surrogacy agreement is valid unless the child whose conception is contemplated in the

Section 292(1)(a).

6 There have been concerns expressed that South Africa may have been or be a destination for international surrogacy as in an early case, the commissioning fathers were respectively a Danish and Dutch citizens; however they alleged they were domiciled in South Africa. See Ex Parte WH and others 2011 (6) SA 514 (GNP) and J. Heaton, 'The pitfalls of international surrogacy: A South African family law perspective' (2015) 74 THRHR 24.

7 Section 292(1)(c) and (d). The domicile requirement pertaining to the surrogate may be waived by a High Court on reasonable cause shown, e.g. if the intended surrogate is a relative living abroad.

8 Section 293(1) and (2). If the husband or partner of the surrogate who is not genetically related to the child to be born unreasonably withholds consent, his consent may be dispensed with by a court.

9 Section 1 of the Children's Act 38 of 2005 defines a gamete as 'either of the two generative cells essential for human reproduction.' 
agreement is to be effected with the gametes of both of the commissioning parents, or, if that is not possible due to biological, medical or other valid reasons, the gametes of at least one of them. This requirement was the subject of protracted litigation, finally ending in the Constitutional Court in $A B$ and others $v$ Minister of Social Development and Others (Centre for Child Law intervening as Amicus Curiae) in 2016. ${ }^{10}$ Upon being advised that, because she was unable to provide gametes as a single person, she was ineligible for surrogacy, the applicant mounted a constitutional challenge to the validity of s. 294, arguing that the genetic link requirement violated her rights to equal treatment, to reproductive autonomy and to dignity (amongst others). Pitted against this was the question whether the child's best interests and right to know his or her genetic origins outweighed the applicant's claims to the constitutional violations alleged. ${ }^{11}$

In the High Court, $A B$ was successful, insofar as the judge ruled the 'genetic link' requirement to be unconstitutional, striking down the impugned section, and referring the matter to the Constitutional Court for confirmation (as required by the Constitution). A critical factor which prompted the High Court to declare s. 294 provisionally unconstitutional was the differentiation in law between the use of surrogacy and the use of IVF procedures, as spelt out in the regulations to the Health Act (referred to above). The IVF regime does not require that the parent or parents of a child to be conceived through IVF donate their gametes. In the view of the High Court, this amounted to differential treatment, even though it was conceded that the two procedures - IVF and surrogacy - were fundamentally different.

The Constitutional Court reversed the decision of the High Court. The Constitutional Court regarded it as significant that the impugned provision falls under the overarching principles of the Children's Act, such as the principle that the best interests of the child must be applied in all decisions taken under the Act. Turning to the question of discrimination, the Constitutional Court

$10 A B$ and others $v$ Minister of Social Development and Others (Centre for Child Law intervening as Amicus Curiae) CCT 155/15, discussed in S. Florescu and J. Sloth-Nielsen, 'Visions on Surrogacy: From North to South: the approach of the Netherlands and South Africa to the issue of surrogacy and the child's right to know his origin' [2017] International Survey of Family Law, 239-58.

11 The Minister of Social Development, as the custodian of the Children's Act, opposed the application on several grounds, namely that: (a) It was not only $A B$ 's rights that were at issue, but also those of the child to be created by
the surrogate mother and donor(s). The prospective child had the right to know its genetic origins.
(b) The adoption process in South Africa catered for AB's need to have a child.
(c) To allow a single infertile person to create a child with no genetic link to her would result in the creation of a 'designer' child. This would not be in the public interest.
(d) Section 294 assists to prevent commercial surrogacy from taking root. 
majority ${ }^{12}$ affirmed that mere differentiation does not necessarily amount to 'irrational' discrimination; moreover, IVF and surrogacy were regulated under completely different statutes, with different objectives.

According to the court, '[t]he requirement of donor gamete(s) within the context of surrogacy indeed serves a rational purpose - the public good chosen by the lawgiver - of creating a bond between the child and the commissioning parents or parent. The creation of a bond is designed to protect the best interests of the child-to-be born so that the child has a genetic link with its parent(s). Therefore, a rational connection exists.' ${ }^{\prime 3}$ Second, it is rational because it safeguards the child's genetic origin, in the best interests of the child, in the view of the court. ${ }^{14}$ And third, an IVF parent using a double donation gametes would have gestational links to the child to be born.

Having established the rationality of the provision, the next issue to consider was whether it discriminated unfairly against the applicant on the grounds of her infertility? It did not, according to the court. 'The parent still has available options afforded by the law: a single parent has the choice to enter into a permanent relationship with a fertile parent, thereby qualifying the parent for surrogacy. It is therefore the exercise of this personal choice that disqualifies her, not her infertility or the impugned section. ${ }^{15}$ Having found no discrimination, the court did not need to deal with the question as to whether the discrimination was unfair.

This majority decision has not been welcomed in all quarters, as the reasoning of the majority was not entirely convincing. Moreover, the suggestion that the infertile applicant find a fertile partner for the purposes of conception with nondonor gametes does not seem judicious, and smacks of a different form of baby shopping. The finding of the Constitutional Court has, however, lead to a South African Law Reform Commission investigation into the rights of children to know their biological origins ${ }^{16}$ more generally and an Issue paper was released on the topic in $2017 .{ }^{17}$

12 The majority/minority split was $7-4$. The minority also wrote a lengthy judgment (which is reproduced first, with the majority following).

$13 A B$ and others $v$ Minister of Social Development and Others (Centre for Child Law intervening as Amicus Curiae) CCT 155/15 para. 287, above n. 10.

14 Ibid. para. 288. The court compares the disqualification of persons unable to donate a gamete to those with defective vision (blindness) or uncontrolled epilepsy and uncontrolled diabetes mellitus, who are disqualified from obtaining a driver's license.

15 Ibid. para. 302.

16 Section 41 of the Children's Act provides that a child born as a result of artificial fertilisation or surrogacy or the guardian of such child is entitled to have access to any medical information concerning that child's genetic parents and to any other information concerning the child's genetic parent but not before the child reaches the age of 18 years. Subsection 41(2) provides however, that information disclosed as set out here may not reveal the identity of the person whose gamete was or gametes were used for the artificial insemination of the identity of the surrogate mother.

17 'The Right to Know One's Own Biological Origins' South African Law Reform Commission Issue paper 32, Project 40, 20.05.2017. The Issue paper expresses the concern that the 
Section 295 sets out the requirements for a court to confirm a surrogacy agreement, which are elaborated ${ }^{18}$ more closely under Section 4 below, as they pertain mainly to the eligibility requirements of for the commissioning parents and for the surrogate. Section 295 requires that the agreement contain details of the consents, genetic origin of the children, when artificial fertilisation will take place, termination of the agreement and the effect of termination of the agreement. ${ }^{19}$ Furthermore, the agreement must spell out adequate provisions for the care, contact, upbringing and general welfare of the child that is to be born in a stable home environment, including the child's position in the event of the death of the commissioning parents or one of them, or their divorce or separation before the birth of the child. ${ }^{20}$

The bare requirements of the Children's Act in respect of the contents of a surrogacy agreement have been supplemented by judicial guidance on the contents of surrogacy agreements. Notably, in Ex parte $W H,{ }^{21}$ a case in which an agency had facilitated the contact between the commissioning parents and the prospective surrogate, the court wanted considerable additional details to be filed on the role of that agency, such as all agreements concluded between the commissioning parents, the agency and the surrogate, and details of any sums paid by the commissioning parents to the agency. Full details of payments made by the agency to the surrogate were also required to be produced. The court adversely commented on the provision for payment of 'lump sum' or general amounts under the various categories (health insurance, life insurance, surrogate's various expenditure (maternity clothes, transport)) as these could disguise the payment of compensation. ${ }^{22}$ The court must be appraised of any previous applications for confirmation of a surrogacy agreement, in which jurisdiction they were brought and whether they were successful or not. Proof must be given of police clearance having been obtained, of a report from a clinical psychologist for both the surrogate and a separate one for the commissioning parents confirming their suitability, and a medical report in respect of the surrogate must be attached. In that jurisdiction (Gauteng North, i.e. the Pretoria region), the rules laid down adding requirements to be included in confirmation applications have been supplemented by a Practice Manual for the guidance of legal practitioners. These will be referred to in this chapter where appropriate.

provision of s. 41 of the Children's Act may, especially in the light of the reasoning in $A B$, be unconstitutional.

18 Section 296 provides emphatically that no artificial fertilisation of the surrogate may take place before confirmation of the agreement by a court, or after the lapse of 18 months after confirmation by a court.

19 Exparte WH and others 2011 (6) SA 514 (GNP), para. 39.

20 Section $295(\mathrm{~d})$.

21 Above n. 20.

22 Exparte $W H$, above n.19, para. 29. 
The Act does not provide for regulations to be promulgated in relation to surrogacy. Amendments that have been prepared for the Department of Social Development, but which as yet have not been introduced to Parliament, will seek to add a provision empowering the Minister to produce regulations, and with a view to implementing the requirements added by the court in Ex parte $W H$, which will probably feature in these Regulations. ${ }^{23}$

The Children's Act creates a number of offences related to surrogacy. These are contained in s. 303. First, no person may fertilise a woman in the execution of a surrogate motherhood agreement until the artificial fertilisation has been authorised by a court in accordance with the Act. Second, no person may in any way or with a view to compensation make it known that any person is or might be willing to enter into a surrogate motherhood agreement.

\section{LEGAL PARENTHOOD AT THE TIME OF BIRTH}

The effect of a legally valid surrogacy agreement is that the child once born is to all intents and for all purposes the child of the commissioning parent(s) from birth, according to s. 297(1). ${ }^{24}$ Sections 297 (b) and (c) provide that the surrogate mother must hand over the child as soon as reasonably possible after the birth, and neither she nor her partner (if any) or relatives will enjoy any legal status in respect of the child. Unless specified in the agreement, she will also have no right to have contact with the child. In turn, the surrogate-born child will have no maintenance or inheritance claim against the surrogate mother or her partner or relatives. She may not terminate the agreement once artificial fertilisation has taken place, ${ }^{25}$ subject to her inalienable right to opt for a termination of pregnancy (see s. 300).

However, a different position prevails if she is genetically related to the child (through ovum donation): in this case, she has 60 days after the birth of the child to terminate the agreement. In this instance, the court must confirm her withdrawal from the contract, and she then incurs no liability to the commissioning parents save for the reimbursement of any expenses that they have covered. ${ }^{26}$ The effect, according to s. 299, is that where the agreement is terminated after the child is born, parental rights vest then in the surrogate, her partner or husband,

\footnotetext{
23 A draft Children's Act Amendment Bill, which includes these proposed provisions, was issued for public comment during September 2018.

24 In respect of legally invalid surrogacy agreement, the consequences would be that the child is for all purposes the child of the surrogate (and her partner, if any) even if there is no genetic link to either of them, Conversely, the commissioning parents would have not status as legal parents (even in one of them is genetically related to the child): s. 297(2).

25 Section 297(1)(e).

26 Section 298.
} 
or if she does not have one, the commissioning father. ${ }^{27}$ Where the agreement is terminated before the child is born, parental rights vest in the surrogate, her husband or partner if any, or if none, the commissioning father as from the time of birth. ${ }^{28}$ The surrogate mother, her husband or partner, or where applicable the commissioning father, are obliged to accept the responsibilities of parenthood. Subject to the instance that the surrogate has no husband or partner, triggering the allocation of parental rights to the commissioning father, the commissioning parents in all other instances have no rights towards the surrogate-born child. ${ }^{29}$

A child born of a surrogacy arrangement which does not comply with the requirements of the Act is deemed for all purposes the child of the surrogate and not the commissioning parent(s). ${ }^{30}$

No artificial fertilisation of the surrogate may take place before the confirmation of the agreement by a court, or after the lapse of 18 months from the date of confirmation. ${ }^{31}$ In Ex parte $M$ and others ${ }^{32}$ the court was confronted with just such a fait accompli as this section tried to prevent. The application for confirmation was made when the surrogate was already 33 weeks pregnant. ${ }^{33}$ The fertilisation had taken place on the basis of a verbal agreement between the parties, who had used the father's sperm. The questions facing the court were twofold: was the court competent to confirm the agreement notwithstanding non-compliance with s. 296? And what is to be required in cases like the present, i.e. on what basis could the court exercise its discretion to confirm an agreement for which prior authorisation was not obtained? For the record, the pregnancy resulted from the use of a donor egg and sperm from the commissioning father.

The court held that the Act does not clearly state what powers such court may have to confirm ex post facto an agreement, and what the status of such agreement (valid or invalid) might be. However, at common law, this would be an unlawful agreement, and therefore unenforceable. Courts would normally be slow to interpret a statute in such a way as to condone illegality. But, the court noted, a surrogacy contract is a contract of a special kind, raising issues such as the best interests of the child to be born, the right to dignity, and the

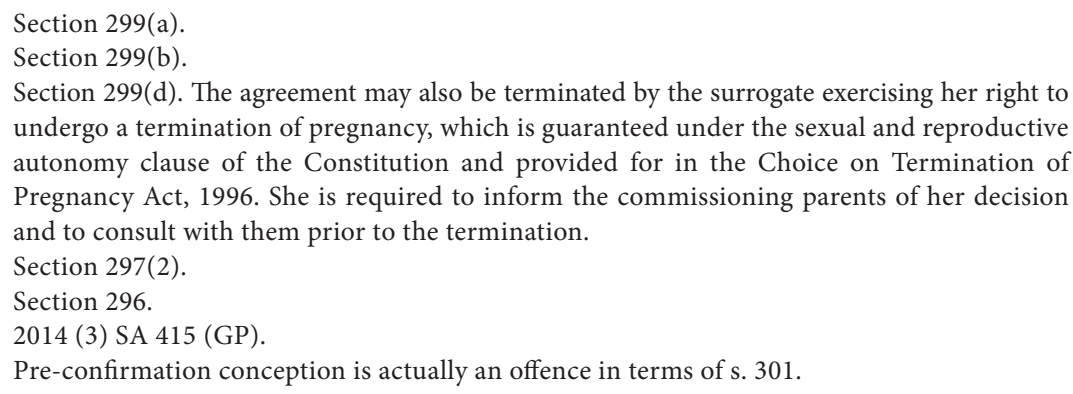
undergo a termination of pregnancy, which is guaranteed under the sexual and reproductive autonomy clause of the Constitution and provided for in the Choice on Termination of Pregnancy Act, 1996. She is required to inform the commissioning parents of her decision and to consult with them prior to the termination. 
surrogate's right to security in and control over her body. Hence, the judge interpreted her mandate to include a discretionary power to condone the late submission of the agreement, for the most part inspired by the best interests of the child whose birth was imminent. It is widely thought, though, that the judgment involved considerable stretching of legal principle to arrive at the desired result.

\section{ELIGIBILITY FOR SURROGACY}

\subsection{ELIGIBILITY CRITERIA FOR WOMEN ACTING AS A SURROGATE}

Section 295 spells out the eligibility criteria for women desiring to act as a surrogate. These are: that she is competent to enter into the agreement; that she is in all respects suitable to act as a surrogate mother; that she understands and accepts the legal consequences of entering into an agreement in terms of this Act; that she is not using surrogacy as a source of income and that she is entering into the contract for altruistic reasons; that she has a documented history of at least one pregnancy and viable delivery; and that she has a living child of her own. Ex Parte WH confirmed that a court will require a proper psycho-social report relating to the surrogate to be attached to the papers.

A recent case did illustrate the willingness of the court to probe the suitability of would-be surrogates with some diligence. In Ex Parte $K{ }^{34}$ the court raised as a matter of concern (inter alia) that the prospective surrogate was only 20 years old, that she had met her husband (the fourth applicant) when she was only 13 years old, had had her first child at 16 , whereupon she dropped out of school prematurely. She had another child two years later. The court was concerned that, as regards her psycho-social status, she did not appear to have made good decisions in her best interests as a teenager, and that there was nothing in the papers to indicate that she had gained the maturity to understand the implications of her decisions. ${ }^{35}$ For this, and other reasons discussed below, the court did not find her suitable to serve as a surrogate mother. ${ }^{36}$

Although there is no explicit age (upper or lower), one website of a local clinic involved in surrogacy requires the surrogate to be no older than 42 years of age.

Case no. 14341/17, Gauteng Local Division, Johannesburg.

This was relevant to the assessment of whether she understood the implication of handing over the child upon birth.

36 Paragraphs 21 and 22 of the judgment. 


\subsection{ELIGIBILITY CRITERIA FOR COMMISSIONING PARENTS}

As mentioned, according to s. 295, the commissioning parents must be unable to give birth to a child, and that condition must be permanent and irreversible. They must be competent to enter into the agreement, be in all respects suitable to accept the parenthood of the child that is to be conceived; and understand and accept the legal consequences of the agreement to be confirmed. Case law has confirmed that medical supporting evidence of the pregnancy or conception infertility of the would-be commissioning parents must be provided (unless the commissioning parent is single or a same-sex (male) couple).

The issue of age(s) of the commissioning parents has not surfaced eo nomine, although there were informal concerns raised by child rights advocates at the time of the $A B$ decision that the principal applicant was already in her late fifties by the time of the application for a declaration of constitutional invalidity which, if successful, would have paved the way for her to enter into a surrogate motherhood agreement.

\subsection{ROLE OF THE CHILD'S BEST INTERESTS IN ASSESSING ELIGIBILITY}

A potentially controversial judgment was recently handed down by the High Court in Pretoria. ${ }^{37}$ Two men seeking confirmation of a surrogacy agreement were unsuccessful. It came to the attention of the judge before whom the matter served that the second applicant, $\mathrm{HN}$, did not want his sexual orientation made public and that he and partner CJD do not live together. ${ }^{38}$ The court noted that his need to be discreet about his sexual orientation was occasioned by his career as a medical specialist, as rumours about his sexual orientation had in the past impacted negatively on his practice. However, the court raised this as a flag with potential consequences for the child's best interests:

'The questions that need to be considered by the Court is how the fact that the parties do not live together, and how the fact that $\mathrm{HN}$ does not want his sexual orientation to be made public will impact on the best interest of the child. It is of no importance at all that CJD and $\mathrm{HN}$ are homosexual, the fact however is that the specific situation may impact on the interest of the child to be born. ${ }^{39}$

\footnotetext{
37 Ex Parte CJD and others (Centre for Child Law intervening as amicus curiae) (case no. 53131/2017, North Gauteng High Court).

38 The third and fourth applicants are the potential surrogate and her partner.

39 Paragraph 4 of the (as yet unreported) judgment.
} 
The fact that the parties wanted to be discreet about their private life, according to the court, did not extend to being discreet about their role(s) as parents of a child born of a surrogacy agreement. The court provided examples of such possible impact: an excited toddler running to his father in a public place shouting 'Daddy Daddy' - would the father then pretend not to be a parent? What will they tell kindergarten and teachers about who the parents are? Who would attend parent days at school?

Citing the requirement that the court must have as uppermost the best interests of the child or children to be born from the surrogacy agreement, ${ }^{40}$ the court opined that however wide the Act is in permitting persons involved in different (permanent) family type relationships to qualify for confirmation of a surrogacy agreement, the court will still have to determine whether the way that the permanent relationship is structured will be supportive of raising a family. ${ }^{41}$ The court found it difficult to conceptualise of a family unit when it is clear from the start that the commissioning parents would not be living together and sharing a household. ${ }^{42}$ By way of analogy, the court cited those instances where the legislation permits joint adoption, ${ }^{43}$ noting that there must be a joint household with shared rights and responsibilities, according to the intention of the legislature. In this application, the applicants did not explain how they will operate as a family unit, whilst not sharing a household. Stressing that the judgment did not preclude an application by one partner as prospective commissioning parent, or a joint application if the second applicant were to be more open about his sexual orientation and status in the relationship, in future, the best interests of the child (to be born) resulted in the court refusing to confirm the application.

\section{TRANSFERRING PARENTHOOD}

\subsection{LEGAL PROCESS}

Due to the a priori legislative determination of the allocation of legal parental status once a surrogacy agreement has been confirmed by a High Court (as discussed in Section 3 above), there is no post-birth transfer of parenthood, as is the case in other jurisdictions.

\footnotetext{
40 Exparte WH 2011 (6) SA 514 at 517 para. 4: 'Children occupy a special place in the cultural, social and legal arrangement so most societies. That this is so is understandable in recognition of both the vulnerability of children and the almost instinctive need to advance their wellbeing and ensure their protection, as well as the compelling human and social imperative to pursue and further their best interests ....

41 Paragraph 18 of the unreported judgment.

42 Paragraph 21.

43 Section 231(1) of the Children's Act.
} 
Part I. Western Perspectives: The Regulatory Approach

\subsection{RIGHTS OF CHILDREN}

Section 41 of the Children's Act makes provision for a child born as a result of surrogacy, or the guardian of that child, to have access to any medical information or other information concerning the child's genetic parent(s) after the child reaches the age of 18 years. This is consistent with the object of s. 294 to ensure that the child becomes aware of its genetic origin. This is so even if the provision does not allow access to information regarding the identity of the surrogate mother in terms of s. 41(2) (AB para. 254).

\section{AGENCIES AND CRIMINALISATION}

The involvement of agencies surfaced in the first reported case after the coming into operation of the Children's Act, Ex parte WH, where the court was at pains to emphasise that the involvement of agencies raised the real risk of 'wombs for hire' and unauthorised payments passing between commissioning parents and agency, or agency and surrogate. The court then stressed that only payments authorised by the Act are permitted. Section 301 lists these as follows: claims directly related to the artificial fertilisation and pregnancy and birth of the child; expenses related to the confirmation of the surrogacy agreement itself; loss of earnings suffered by the surrogate in consequence of the surrogacy agreement; insurance for the surrogate mother to cover for death or disability; and bona fide professional medical or legal services.

The court required, further, when an agency was involved in the surrogacy arrangement, for the following additional documents to be submitted with the papers: the business of the agency; whether any form of payment is being paid to or by the agency for any aspect of the surrogacy; what exactly the agencies involvement was regarding: (i) the introduction of the surrogate mother; (ii) how the information regarding the surrogate mother was obtained by the agency; (iii) whether the surrogate mother received any compensation at all from the agency or from the commissioning parents. ${ }^{44}$

In a recent matter, Ex parte HPP, ${ }^{45}$ the court noticed that a particular person was to act as a so-called surrogacy coordinator providing 'surrogacy facilitation services'. This raised the question as to whether s. 301 of the Children's Act was being contravened by the submission of a contract (between the parties and the surrogacy coordinator), and whether the court could confirm a surrogacy agreement if it found that the agreement between the parties and the coordinator was unlawful, but all other requirements were met.

\footnotetext{
$44 \quad$ Paragraph 66.

45 Unreported case no. 45037/16.
} 
Upon inquiry as to what this service entailed, and whether it was to be paid for, the court established that it included: guiding and advising the surrogate; a referral to a clinical psychologist; assisting with any mediation with the surrogate, if applicable, during the gestational period; if required, to manage any dispute resolution; in general, to oversee the entire surrogacy 'journey'. An amount of R5,000 was to be invoiced for this service, which the applicants were happy to pay. It was explicit that no fee would be earned for introducing the surrogate to the intended parents.

The court, having noted the interests of the surrogacy facilitator, advised her of its intention to declare the agreement between herself and the applicants unlawful, so that she could file an affidavit. She responded that she had been offered full-time employment by a fertility clinic as a surrogacy coordinator, which she accepted.

She explained that she herself had acted as a surrogate six times in the past 11 years, and was uniquely placed to provide support services to surrogates; she added that her services included offering round-the-clock emotional support, running a surrogacy support group, and monitoring the surrogate throughout the process. This includes reminders to the surrogate to take her medication, explaining complicated doctors' reports to the surrogate, and preparing the surrogate emotionally for medical procedures.

On evaluation of this supplementary evidence, the court was not convinced that her services do not encroach on legal, medical and psychological terrains. Moreover, the court emphasised, that, like it or not, commercial surrogacy was prohibited in South Africa, and that s. 301 reinforces that only prescribed payments are permitted, on pain of criminal sanction. Payments of introductory fees to facilitate the link between commissioning parents and a potential surrogate are specifically prohibited (and the surrogacy coordinator categorically stated that she did not levy a fee for services other than those authorised by the Act or to persons other than authorised by the Act), are prohibited and any affidavit founding an application for confirmation must state this fact. ${ }^{46}$

The applicant's lawyer argued that the facilitator's fee fell within the ambit of s. 301 exceptions, on the basis that they were expenses 'related to the artificial fertilisation and pregnancy' or those 'related to the birth of the child'. The court dismissed this, stating that invaluable though her services might be, they are not authorised by the Act and therefore the agreements between her and the commissioning parents were declared unlawful and unenforceable. The primary concern of the court was the possibility of commercial surrogacy being furthered through the back door, particularly that fees will be charged de facto for recruiting surrogates and introducing them to commissioning parents.

46 In $W H$, the surrogates were introduced to the commissioning parents by an egg donation agency, free of charge. 
As to the impact of an illegal collateral agreement upon the surrogate motherhood agreement, the court held that there was no danger that the rights of the unborn child would be affected, as the fertilisation process had not yet commenced. The rights of the commissioning parents would be impinged only to a limited extent as they could still enter into another surrogacy agreement which was not affected by a tainted collateral agreement. The court had a discretion according to applicable contract law to establish whether the unlawful contract had tainted the lawful contract to the extent that the lawful contract cannot be endorsed. The surrounding circumstances in this case having been briefly perused, including the fact that the applicants were unaware of the possible illegality of a facilitation agreement, the court confirmed the surrogate motherhood agreement sans the collateral illegal agreement.

In Ex parte $K{ }^{47}$ the court expressed grave concern about the purportedly altruistic nature of the surrogate's willingness to act as such. She came seemingly from poor socio-economic circumstances, and had no other income. The municipal rates bill for the property where she lived with extended family members was deeply in arrears. The surrogate and her husband had not provided a full statement of assets and liabilities to the court. She was to receive a flat fee of R4,000 (US\$340) per month to start with, escalating to R6,000 (US\$500) per month once a pregnancy was confirmed (for her to hire a domestic worker to assist with the extra burden of the pregnancy and her own two small children). Noting that the court in $W H$ had specifically discouraged the payment of generic amounts, the court said it was not convinced that these amounts (of R4,000 and R6,000) were justified, as insufficient information had been placed before the court to warrant that the prospective surrogate mother was not using surrogacy as a form of income. The contract was not confirmed.

The court also commented adversely on some other aspects of third-party involvement in this surrogacy arrangement. The court noted that the surrogate and commissioning parents were introduced to one another by a clinic which operates an internal surrogacy programme. They also offer other services; the assessment report reflects that the psychologist had an office based at the same premises as the clinic; the same psychologist compiled the reports for both the surrogate and the commissioning parents; it also appeared that the same medical doctor who would undertake the artificial fertilisation was also responsible for compiling the reproductive medical reports. His address also was the same as that of the clinic. No information was provided to the court as to whether these complementary services were paid for by any of the parties or not. Further, if they were paid for, this might hamper the objectivity of the professional assessment. Given that it was found that it was unlikely that the potential surrogate in this case had the necessary maturity to realise the implications of her decision, the 
court said 'this points for the need for medico-legal experts involved in the surrogacy process to be impartial in perception and in fact, given the assistance they offer to the Court in this regard. They owe their allegiance to the Court and not to the parties to the SMA. ${ }^{48}$

In the premise, the court was not satisfied about the non-disclosure of the relationship between the medico-legal professionals and the clinic, such that the risk of a commercial surrogacy could be eliminated.

\section{INTERNATIONAL SURROGACY ARRANGEMENTS}

The terrain of international surrogacy relative to South Africa is at once simple and complicated. As pointed out, the starting point is that unless authorised by a court in the case of an intended surrogate, the parties must be domiciled in South Africa. Domicile is a legal concept, and is not equatable to habitual residence. It can be established quite quickly, provided that the requisite intention to establish a domicile is in place. The $W H$ case, as mentioned, involved a Dutch and a Danish national, who did aver that their domicile was South Africa, though this has been disputed in academic circles, who have raised the spectre of international surrogacy tourism. ${ }^{49}$ A surrogacy agreement concluded by foreign nationals who are not domiciled in South Africa would be invalid and unenforceable, regardless of whether the surrogacy is altruistic or commercial. The commissioning parents would acquire no rights in respect of the surrogateborn child, and would also likely be ineligible for adoption, given the requirements of s. 25 of the Children's Act which foresees such applications as being treated as inter-country adoptions, which must be dealt with in accordance with the Hague Convention on Intercountry Adoption (1993), which South Africa has ratified. Satisfying Hague Convention requirements include the principle of subsidiarity, meaning that no suitable domestic adoption possibilities exist. ${ }^{50}$

The position of a South African engaging in surrogacy abroad is murky. The law does not prohibit South Africans from engaging in surrogacy abroad. There would be little reason for them to do so, since altruistic surrogacy is legal, unless they lacked or did not want to donate their own gametes, or preferred medical services offered elsewhere. ${ }^{51}$ Their legal parentage status could be uncertain, and if commercial surrogacy was at stake, the public policy exception of common law might result in South African courts declining to recognise the legal tie between the commissioning parents and the child. Recently, an enquiry regarding

\footnotetext{
48 At para. 27. SMA is the abbreviation for surrogate motherhood agreement. J. Heaton, above n. 6, p. 32.

For this reason, the Children's Act established a Register of Adoptable Children and Prospective Adoptive Parents, to enable domestic matching to occur: s. 232.

51 J. Heaton, above n. 6, p. 40.
} 
parentage was received by a child rights advocacy clinic regarding twins born to a South African mother arising from a surrogacy agreement concluded and fulfilled abroad. Upon her return to South Africa, she died, and an uncle, based in South Africa, was exploring the possibility of formalising his parentage status in respect of the two children. The matter is yet to be resolved. ${ }^{52}$

The HPP case discussed above records that the surrogacy coordinator advertised her services on a website and offered services to national and international clients. This included providing for intended parents living out of state, and personal consultation with the surrogate via home visits. This position is potentially illegal in view of the prohibition on payments being received for surrogacy services in s. 301, subject to the exceptions provided for therein. Recently, an anecdotal report surfaced of commissioning parents based in the United Kingdom who have two children born of a South African surrogate. Since there are additional concerns relating to the legality of the alleged court approval, the matter is being investigated. ${ }^{53}$

\section{CONCLUSION}

There is an evident need to foster better oversight over surrogacy as a whole in South Africa. As matters stand at present, the reliance has been exclusively placed on the judiciary to exercise oversight and ensure that the intention of the legislature, especially to prevent commercial surrogacy, is upheld. The cases discussed in this chapter show that, as far as can be ascertained, many judges are performing an excellent job in delving into the details of surrogate motherhood agreements coming before them for confirmation. However, too little information exists about the overall picture: how many surrogacy agreements are being concluded in the country as a whole? What is the overall profile of surrogate mothers? How are the actual payments to surrogate mothers and others (lawyers, clinics) being monitored?

It is therefore proposed that two solutions would improve the surrogacy situation in South Africa: first, the enactment of regulations to the principal law contained in the Children's Act, to spell out in more detail the criteria that the courts are developing related to (for instance) eligibility of surrogates and commissioning parents, authorised payments and the benchmark amounts, ${ }^{54}$ and the role of intermediaries and third parties.

52 K. Ozah, presentation at the Miller du Toit Cloete/University of the Western Cape 21 st conference on child and family law, Cape Town 02.03.2018 (copy on file with the author).

53 Personal communication wth a lawyer representing the South African mother in court proceedings being pursued in the United Kingdom for the return of the children on 25 September 2018.

54 As has been done in the Regulations to the Children's Act prescribing payments for intercountry adoption. 
Second, there appears to be a need for a central authority to collate information and monitor developments. Such agency would have to be established under one or another legal regime, in order for it to have the necessary powers and functions (e.g. to require reporting by fertility clinics and other role players, to investigate cases of potential malpractice and so forth).

South Africa's history of surrogacy is not a recent one: even prior to the enactment of legislation in 2010, clinics had been performing surrogacy services for some 30 years. ${ }^{55}$ However, with the advent of the Children's Act, surrogacy is much more in the public domain, ${ }^{56}$ and subject to judicial scrutiny.

55 Presentation by an obstetrician at a conference on surrogacy in October 2015, Stellenbosch University Faculty of Law. He acknowledged having birthed more than 3,000 surrogate-born babies over the course of his career.

56 Although the Children's Act does prescribe that the identities of the commissioning parent, the surrogate, and the surrogate-born child may not be made public: s. 302 . 
- 